\title{
National OSCE result as parameter outcome of basic clinical skills training during preclinical phase
}

\author{
Risahmawati $\bowtie$ \\ Faculty of Medicine and Health Sciences, Syarif Hidayatullah Jakarta State Islamic University, Indonesia \\ (risahmawatidr@uinjkt.ac.id) \\ Auda, Riva \\ Faculty of Medicine and Health Sciences, Syarif Hidayatullah Jakarta State Islamic University, Indonesia \\ (riva_iwa@yahoo.com) \\ Ardini, Witri \\ Faculty of Medicine and Health Sciences, Syarif Hidayatullah Jakarta State Islamic University, Indonesia \\ (w.ardini@yahoo.com) \\ Marita, Fadhilah \\ Faculty of Medicine and Health Sciences, Syarif Hidayatullah Jakarta State Islamic University, Indonesia \\ (maritafadhilah@uinjkt.ac.id)
}

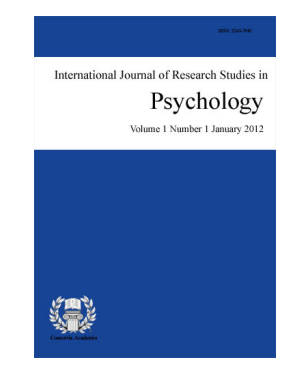

ISSN: $2243-7681$ Online ISSN: 2243-769X

OPEN ACCESS

$\begin{array}{lll}\text { Received: } 27 \text { January } 2015 & \text { Revised: } 16 \text { August } 2014 & \text { Accepted: } 10 \text { September } 2015 \\ \text { Available Online: } 28 \text { September } 2015 & \text { DOI: } 10.5861 / \text { ijrsp.2015.1229 }\end{array}$

\section{Abstract}

Since 2005 we have been teaching basic clinical skills (BCS) such as physical examination, and other procedural skills among medical students. Objective Structured Clinical Examination (OSCE) is a tool to assess those skills. On 2013 OSCE was implemented as national examination for all of Indonesian graduated medical students. National OSCE examined eight areas of competency. This study described national OSCE results to evaluate students in each area of competency and give suggestion to curriculum team to make appropriate improvement. Comparison were accomplished in each of the competency within OSCE. Results show that fifty three students enrolled in national OSCE 2013. Candidates' skills to do history taking was the best in all OSCE period, followed by patient's education and professionalism (mean over 77\%). While, candidates seem less competent in diagnose and giving pharmacotherapy and non-pharmacotherapy (mean less than 60\%). Physical examination and clinical procedures were quite good (mean around 60\%). During preclinical phase students repeat history taking in every block. This repetition has great effect in skills mastery. While, students need more exercise to diagnose clinical case and giving treatment. This study revealed good competency in process skills (history taking, patient education and professionalism) while content skills (diagnosis and giving treatment) still need improvement. National OSCE result gave sufficient data for some improvement in learning process during preclinical and clinical phase.

Keywords: basic clinical skills; national OSCE; medical students' competency; exit exam; process skills; content skills 


\section{National OSCE result as parameter outcome of basic clinical skills training during preclinical phase}

\section{Introduction}

Faculty of Medicine and Health Sciences (FMHS) Syarif Hidayatullah implemented problem based learning (PBL) curriculum. Medical education at FMHS Syarif Hidayatullah consists of two phases, pre-clinical and clinical phase or clerkship. During preclinical phase students were taught basic clinical skills (BCS) as well as basic clinical sciences. BCS as part of PBL curricula is one of the method which give the students opportunity to expose with clinical skills at a very early stage in medical education (Anggraini, 2012). BCS were taught from first until sixth semester. The sequences of BCS training in daily schedule are five skills in every long module and two skills in short module, at the second session of each skill there are tutor evaluation. There are three assessments to evaluate student:

$>\quad$ Peer review; student assess another students

$>$ Self-assessment: student asses himself honestly whether it is competent

$>$ Tutor assessment: tutor assess whether the student has competent or not

Objective Structured Clinical Examination (OSCE) is a tool to evaluate those skills, after three assessments. Local OSCE is a comprehensive examination for student, held once a year at the end of academic year as part of clinical reasoning module examination. To prepare our student in national OSCE, since 2012 we use the same format with national OSCE. National OSCE was implemented as part of national examination of competency for all of Indonesian graduated medical students as a requirement to obtain certificate of competency. National OSCE examined eight areas of competencies, such as history taking, Physical examination, Clinical procedures, determining working diagnosis/differential diagnosis, no pharmacy-therapy and pharmacotherapy, communication and professionalism. Since BCS implementation in 2005 there were no evaluations on how BCS affect the result of national OSCE. This study described national OSCE results to evaluate students in each area of competency and give suggestion to curriculum team to make appropriate improvement.

\subsection{Learning Context}

Faculty of Medicine and Health Sciences (FMHS) Syarif Hidayatullah implemented problem based learning (PBL) curriculum since its first generation medical student in 2005. PBL approaches integrated educational strategies to achieve learning goals through optimizing student centered approaches (Anggraini, 2012). In a student-centered problem-based curriculum, students learn by actively solving problems rather than by passively absorbing information. The PBLC uses a problem as the starting point for student learning (Burrow, 1989).

There are three important ways of PBL curriculum

$>\quad$ Integration of basic science materials into a single program. In PBL curriculum way's basic medical sciences are learned concurrently and always in the context of a particular health problem

$>\quad$ The students activities emphasize on learning actively in their own education, the responsibility to achievement of learning goals are in student's hand.

$>\quad$ Students must practice skills that will encourage them to become self-directed learners for the rest of their lives as an addition to biomedical training (Burrow, 1989).

FMSH UIN also implemented PBL curriculum key featured that adopted from Mc Master University (Anggraini, 2012). The key features of the PBL curriculum are to analyze health care problems as the main method of acquiring and applying knowledge; to develop life-long learning skills; and to use small group, tutorials (six - ten students) with a faculty tutor in each group (Neufeld, Woodward, \& MacLeod, 1989). An added value of the PBL curriculum is teaching basic sciences in the context of a clinical problem, whether real or 
National OSCE result as parameter outcome of basic clinical skills training during preclinical phase

hypothetical, which makes it attains two goals: to make knowledge more relevant and retrievable, and to foster the development of specific reasoning (Walton, 1989).

BCS as part of PBL curricula is one of the method which give the students opportunity to expose with clinical skills at a very early stage in medical education (Anggraini, 2012). Clinical skills are any discrete and observable act of clinical care. There are certain requirements to perform excellence clinical skills before doing the practice in real patient. Skills learning need demonstration of skills proficiency, performance of clinical skill s must be observable. Evaluations of skills are a set of observation, repetition and constructive feedback from trained observer, such as senior physicians or experienced patient. All of those efforts are required to continually refine and improve clinical skills. Professional skill learning is a developmental process that is continually shaped and refined throughout the physician's career. Cultivation of skill acquisition in the foundation years of undergraduate medical education results from exposure to sequentially more challenging clinical learning experiences, repeated practice opportunities, observation and feedback based on definable performance outcomes, and self-directed proactive learning (AAMC, 2005).

Medical education is a set of structured educational strategies to prepare a doctor in individual patient care, achieving clinical practice competencies and clinical skills expertise. Individual patient care skills trained by case-based learning, clinical practice competencies trained by skill education objectives and clinical skills expertise prepared by basic clinical skills learning. Medical schools should implement a clinical skills curriculum that incorporates the developmental nature of learning, including the designation of expected levels of skill performance (AAMC, 2005). Basic clinical skills curriculum in FMHS UIN in has been developed from its generic formula in 2012. There are some additions of some skills and applying new format of mapping, BCS was integrated with the module that were running. For example, in respiratory module, we taught physical examination of the lung and a set of clinical skills; data interpretation, procedural skills and communication related to lung diseases. There are total 20 hours of BCS in every long module and 8 hours of BCS in short module (Anggraini, 2012).

Each BCS held for two hours. Simultaneously BCS training are allocated about 20 hours in six weeks module. One tutor for one group of student consists of 8-12 students. Tutors are doctors who have been trained in specific clinical skills by specialist who is more competent for certain skills. Student group will take turn practicing clinical skills in accordance with the schedule. By the time they practice communication and physical examination, they practiced between friends or using a standardized patients or peer. When practicing procedural skills, they use mannequin or tools that has been provide by skill lab. Skills laboratories provide a safe environment for practice and learning processes (Anggraini, 2012).

In 2005 FMHS Syarif Hidayatullah apply four steps (Peyton's Four Step Approach) in implemented the BCS, which adapted from medical Faculty of Indonesia.

$>$ Demonstration: Trainer demonstrates at normal speed, without commentary.

$>$ Deconstruction: Trainer demonstrates while describing steps.

$>$ Comprehension: Trainer demonstrates while learner describes steps.

$>\quad$ Performance: Learner demonstrates while learner describes steps (Nikendei et al., 2014).

Started from academic year 2012, FMHS Syarif Hidayatullah began implementing the five steps in the BCS (George \& Doto, 2001; Anggraini, 2012).

$>$ Conceptualization: Understanding the cognitive elements of skills

$>$ Visualization: the learner must see the skill demonstrated in its entire from beginning to the end.

$>$ Verbalization: the learner must hear an explanation of the steps of the skill along with second demonstration

$>$ Practice: the learner having seen the skill, heard explanation and repeated explanation, now performs the skill

$>$ Correction and reinforcement: skill error immediate correction, positive reinforcement for good performance. 
Medical students from FMHS' clerkship will be held at Fatmawati Hospital as a major teaching hospital. Cisarua Hospital, Marzuki Mahdi Hospital, and Bekasi Hospital as other teaching hospitals. Students group consisted of 9 to 15 students. They will follow the rotation of major or minor stage (Anggraini, 2012). Minor stages are the phase of students clinic held for 4 weeks.

Psychiatry, neurology, cardiology, pulmonology, dermatology, ophthalmology, ear, nose and head (ENT), emergency, and geriatric are minor stage. Major stages are the phase students' clinic held for 10 weeks. Pediatric, internal medicine, surgery, obstetrics and gynecology, family medicine are major stage. After the major and minor stage, they will begin elective rotation (Anggraini 2012). During clinical phase students has many opportunities to learn, practice and refine all the basic clinical skills taught in pre-clinical phase. After finished all clinical rotation student has to pass Indonesian doctor examination of competency to obtain certificate of competency.

\section{Methods}

A List of competencies area those student should be competent has been described. All of these skills were taught during the preclinical phase. At the preclinical phase academic staff demonstrated, guided, and tested all the skills at the end of each blocks. Before examination by tutor student has some opportunity to repeat practicing the skills by themselves with peer evaluation and tutor supervision. The students were assessed in these skills during preclinical phase at the end of academic year as local Objective Structured Clinical Examination (OSCE). During the examination both patients as well as models were used depending upon the skills tested. Later they carry out these skills in the ward in patients under supervision of the interns and registrars. At the end of clinical phase the student enrolled in national OSCE examination as part of medical doctor competency test. The students are examined using a structured checklist. We compared all candidates' average score in national OSCE examination to maximum scores in each competency in each OSCE period during 2013. Result of comparison presented in percentage.

\section{Results}

Fifty three students enrolled in national OSCE during 2013, divided into 4 periods. Figure 2 presented average of percentage of FMSH UIN candidates compare to maximum score for each competency in national OSCE results in each period of examination.

Table 1

Characteristics of subject

\begin{tabular}{lcc}
\hline & Characteristics Subject & Total (\%) \\
\hline $\begin{array}{l}\text { Male } \\
\text { Female }\end{array}$ & Gender & $17(32 \%)$ \\
& & $36(68 \%)$ \\
February & Graduation Period & \\
May & Formative Assessment National OSCE & $30(56 \%)$ \\
August & Summative Assessment National OSCE & $12(23 \%)$ \\
November & & $9(17 \%)$ \\
\hline
\end{tabular}


National OSCE result as parameter outcome of basic clinical skills training during preclinical phase

Table 2

Average of percentage of FMSH UIN candidates compare to maximum score for each competency in national OSCE results in each period

\begin{tabular}{llcccc}
\hline & Skills to be Examined & $\begin{array}{c}\text { February } \\
(\mathrm{n}=30)\end{array}$ & $\begin{array}{c}\text { May } \\
(\mathrm{n}=12)\end{array}$ & $\begin{array}{c}\text { August } \\
(\mathrm{n}=9)\end{array}$ & $\begin{array}{c}\text { November } \\
(\mathrm{n}=2)\end{array}$ \\
\hline 1 & History Taking & 82 & 86 & 82 & 91 \\
2 & Physical Examination & 56 & 54 & 76 & 67 \\
3 & Clinical Procedures & 50 & 59 & 70 & 75 \\
4 & Working Diagnosis/Differential & 57 & 53 & 67 & 54 \\
& Diagnosis & & & 67 \\
5 & Non Pharmacotherapy & 55 & 53 & 68 & 53 \\
6 & Pharmacy-therapy & 54 & 53 & 77 & 84 \\
7 & Communication and personal & 79 & 77 & & 78 \\
\end{tabular}

To analyze the result we compare average score of OSCE participant from FMSH UIN to maximum score in national OSCE. The ability to show and perform history taking during national OSCE examination was the best in every period of examination among all skills, with overall average more than $80 \%$. Others skills which achieved very good rescore are communication, giving personal education for patient, and also performing professionalism during the test with overall average more than $70 \%$. While, candidates seem less competent in diagnose and giving pharmacotherapy and non-pharmacotherapy (average less than 60\%). Physical examination and clinical procedures were quite good (average around 60\%). Overall, participant from FMSH UIN showed positive trend from first until last period of OSCE for performing history taking, clinical procedures, communication and personal education, also professionalism. There are three others skills which obtained average score around 50\% (minimum $41 \%$ and maximum $68 \%$ ); performing the ability to do pharmacotherapy and non-pharmacotherapy, skills to determine working diagnosis and differential diagnosis. Those three skills are related each other. There are some significant increase score for clinical procedures skills in every period of OSCE. While history taking skills and professionalism showed a stabile score in every period of OSCE (average over $70 \%$ ).

\section{Discussion}

This study is trying to describe whether the teaching/learning of basic clinical skills in our preclinical phase have been effective in imparting the desired level of competencies in these skills. Some essential skills examined in national OSCE examination are routinely given in every block module, such as history taking, communication, education for patient, and professionalism, two hours in every module as an integral part of the module. History taking skills were taught almost in every module for two hours with variable of case scenarios. The superior skills mastery of performing history taking, communication, giving personal education for patient, and also performing professionalism showing good indicator of good learning-teaching process during preclinical phase.

Overall result of national OSCE examination reflected the process in preclinical phase. Repetition in some core skills obtained very good score in positive trends in every OSCE period. While, some rarely repeated skills resulted in about the average score. These finding are in line with previous study that some medical schools cannot rely on clerkship experiences alone to provide adequate basic skills training. During preclinical phase students repeat history taking in every block. This repetition has great effect in skills mastery; while students 
need more exercise to diagnose and giving treatment, pharmacotherapy and non-pharmacotherapy. These finding assume there was a gap in preclinical and clinical phase learning-teaching process. Preclinical phase should be a preparation time for clinical phase. Clinical phase or clerkships is a period of practicing the skills repeatedly under senior doctor and preceptors' supervision in real patient.

To obtained a certain degree of competencies meeting the requirements of qualified medical doctor, student need repeated and constructive feedback in order to continually refine and improve clinical skills performance (AAMC, 2005). It is clearly describe that there were no dichotomy in these two phases. Some of inferior skills mastery obtain by participant from FMSH UIN; are a routine activities in daily practice during clerkship, but this is still a question because we have not make any structured and effective evaluation on how the clerkship's learning-teaching process.

This finding indicates a necessity of improvement in learning-teaching process both in preclinical and clinical phase. In preclinical phase some of skills may apply the teaching method of history taking, professionalism and communication learning-teaching method during BCS training. There are also many possibilities to create appropriate modification in organizing clerkship learning-teaching method to acquire adequate level of competency. In clerkship student need evaluation of skills proficiency by direct involvement of trained observer, such as senior doctor or clinical preceptors. Excellence achievement of clinical skills result from continually repeated performing and practicing basic clinical skills. Student should develop their skills by self-directed learning to practice and perform the skills.

The responsibility to improve the students skills are both in faculty member and also preceptors in teaching hospital. There must be a good relationship between two institutions, which in turn resulted in high competency doctors. This study only focusing the discussion in the effect of preclinical phase learning to clinical skills in national OSCE examination, while student undergone national OSCE examination after clerkship. Previous study showed some medical schools cannot rely on clerkship experiences alone to provide adequate basic skills training. A problem-based learning environment and training in a skills laboratory appear to result in students performing more skills during clerkships. Another study reported some previous studies in the UK and Kuwait have shown that the preparedness and confidence to perform clinical skills were insufficient among new medical graduates (Premadasa et al., 2007).

Confidence to do procedural skills seemed to grow as the year progressed, and this was linked to experience and the successful completion of procedures (Jaschinski, 2008). Assessment of practical skills as part of overall composite examination may not be effective in ensuring that all students have achieved the required level of competency. Practical skills should be evaluated through dedicated formative assessments to make sure that all the students acquire the required competencies (Elango et al., 2007). It will be better if the institution evaluate the effect of teaching-learning process in preclinical and clerkship to skills proficiency. Then every phase has its priority to strengthen and emphasize the skills proficiency in a continuum sequence. A routine assessment of certain clinical skills and repetition during pre-clinical phase may be strong determinants of present finding.

\section{Conclusion}

This study revealed good competency in process skills (including: history taking, patient education and professionalism), while content skills (diagnosis and giving treatment) still need improvement. In addition, longitudinal skills training seems to offer students a well preparation; as for the clinical phase as well as influencing the students' learning abilities, during the clinical phase. National OSCE result gave sufficient data for some improvement in learning process during preclinical and clinical phase.

\section{References}

AAMC, T. F. (2005). Tomorrow doctor's recommendations for clinical skills curricula for undergraduate Medical education. The Association of American Medical College. 
Anggraini. (2012). Medical student handbook. Jakarta: FMHS Syarif Hidayatulah.

Burrow, M. (1989). Problem-based learning: An approach. New York: Springer.

Elango, S., Juttim R. C., Kandasami, P., \& Teng, C. L. (2007). Assessment of basic practical skills in an undergraduate medical curriculum. International e-Journal of Science, Medicine \& Education, 1(1), $41-45$.

George, J. H., \& Doto, F. X. (2001). A simple five step method for teaching clinical skills. Family Medicine, 33(8), 577-578.

Jaschinski, J. (2008). Factors influencing the development of practical skills of interns working in regional hospitals of the Western Cape province of South Africa. South African Family Practice, 50(1), 70. http://dx.doi.org/10.1080/20786204.2008.10873676

Neufeld, V. R., Woodward, C. A., \& MacLeod, S. M. (1989). The McMaster MD programme: A case study in medical education. Academic Medicine, 64, 423-432. http://dx.doi.org/10.1097/00001888-198908000-00001

Nikendei, C., Huber, J., Stiepak, J., Huhn, D., Lauter, J., Herzog, W., Junger, J., \& Krautter, M. (2014). Modification of Peyton's four-step approach for a small group teaching: A descriptive study. BMC Medical Education, 14, 68. http://dx.doi.org/10.1186/1472-6920-14-68

Premadasa, I. G., Shehab, D., Al-Jarallah, K. F., \& Thalib, L. (2007). Confidence in performing core clinical skills: A survey of trainees completing internship training in Kuwait. Bulletin of the Kuwait Institute for Medical Specialization, 6, 68-73. 
Risahmawati, Auda, R., Ardini, W., \& Marita, F. 